\title{
Tradition and Expertise in Academic Library Collection Development
}

\section{Lawrence Thomas}

The tradition of academic freedom in postsecondary institutions has produced organizations in which two modes, one for faculty and one for services, operate side by side. The issue of whether faculty or librarians have primary responsibility for collection development demonstrates the conflict inherent in this bimodal structure. During recent periods of relative affluence, many institutions gave librarians an unprecedented degree of selection responsibility. This raised questions about the kinds of expertise librarians must have and led, in many libraries, to the evaluation of collections. The controversial University of Pittsburgh study is compared with the National Enquiry into Scholarly Communications.

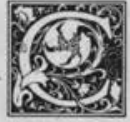

ollection development commands widespread attention even as technology threatens to render society paperless and, presumably, bookless. The success of recent collection development institutes attests to this. The topic is vital because developing library collections is a matter of complex human behavior requiring decisions affected by economics, politics, and scholarship. Spending a limited budget in order to bring users those sources of information most appropriate to their needs is challenging because of the many forms of human interaction required for its accomplishment. Inventing new ways to manage data with machines may create alternative forms of information but does not change the basic mission of collection development.

The purpose of this article is to examine how cultural traditions influence the dayto-day work of collection development in academic institutions. It is assumed that a better understanding of any specific operation within a university, such as the building and organization of library resources, can be gained by analyzing the workings of the parent institution. The in- fluence of tradition is considered because it is a significant force in the academic environment.

The most obvious link between the traditions of academic institutions and their library collections can be found in how the organization makes and lives with its choices. If the parent institution has longstanding customs that guide its decisions, it is likely that these will exert an influence on specific operations. This influence is important because collection development involves the making of many decisions. Moreover, the influence of tradition is apparent not only in the process of choosing a course of action, but in determining who makes decisions, the methods by which they are made, overseeing implementation, evaluating effects, changing or rescinding decisions, and rewarding the people who make them.

Considerable research has been done on decision making, yet these studies rarely provide an overview of organizational behavior that covers the pervasive influence of tradition. Contributions to the literature of organizational behavior, however, do attempt a broader perspective. Two theories in particular are considered here. 
First, theorists agree that the present structure and operating style of colleges and universities have been determined to a great extent by the tradition of academic freedom and the extension of that freedom in the form of tenure. ${ }^{1}$ Because of the need to maintain the autonomy of the individual faculty member as a cultural priority, the classical, hierarchical structure has been modified. Thus, a kind of conglomeration has evolved rather than an organization in which departments and individuals are loosely related and highly autonomous. ${ }^{2}$ This contrasts with most profit-seeking corporations in which departments are highly integrated and have little autonomy.

This description of academic organization may adequately describe the faculty structure, but it does not apply to housing, purchasing, or other support services. In practice, universities prefer a closely coordinated model, similar to the typical industrial corporation. Academic institutions, therefore, tend to have two structures: a laissez-faire, or collegial structure for faculty, and a semiautocractic, hierarchical structure for nonfaculty. Along with hospitals and other professional organizations, these structures have been labeled "double-headed monsters. ${ }^{\prime 3}$ In daily operations, they must cope with the issues that arise from conflict between the two modes of operation. Not to do so may lead to lower productivity.

Conflicts arising from the bimodal system are evident in the libraries on many campuses. Should librarians have faculty status? Should libraries be administered collegially or hierarchically? Should they report to the academic vice-president or the administrative vice-president? Should library directors be considered deans? These questions, basically related to classification, arise systemically in the typical academic environment: on which side of the fence do librarians belong? Much of their work requires the coordination and central control of the hierarchical organization, but much of it, collection development for example, requires an education like that of faculty in the academic disciplines. At the root of this uncertainty is the question of expertise, that is, who is better qualified to build the library collection, faculty or librarians?

Because higher education is responsible for providing society with properly credentialed experts, one might expect that universities would be exceptionally painstaking and skillful in delegating decisionmaking authority to those who have the most appropriate expertise. This is not always the case, however, as is illustrated by the question of who should be responsible for selecting library materials. Because academic tradition rather than an objective analysis of the requirements of the work decides who is best qualified to do the job, practice has a vexed history. To explain further, it is helpful to turn to a second theory found in the literature on organizational behavior. ${ }^{4}$ This is the notion that academic institutions, when selecting new faculty or when evaluating their subsequent performance, tend to place more emphasis on credentials and documented evidence than on determining their actual performance.

"Prior to 1960 , authority for selecting
library materials was almost exclu-
sively in the hands of faculty. This is
still the case on many campuses, es-
pecially small, independent, liberal
arts colleges."

This sweeping claim may appear to be contradicted by stringent peer review procedures. The contradiction fades, in fact, when faculty are asked about how they are evaluated. One survey shows that criteria vary greatly in their significance. ${ }^{5} \mathrm{Re}$ search was the most influential factor in obtaining promotions and other rewards. Teaching was next in importance. This was true even though most faculty spent more time teaching than doing research. Of least importance was a category of other duties called "university service." Library liaison work falls into this category. From this evidence the argument 
can be made that the peer review system is biased and applies criteria selectively so that their weighting does not necessarily correspond to the actual profile of an individual's responsibilities. The system gives responsibility to faculty in areas, such as recommending new publications for the library collection, without ever asking how good their recommendations are.

Prior to 1960, authority for selecting library materials was almost exclusively in the hands of faculty. ${ }^{6}$ This is still the case on many campuses, especially small, independent liberal arts colleges. This practice originated as a simple extension of the institution's traditional approach to assigning responsibility on the basis of disciplinary expertise. The underlying principle is that as a subject specialist the faculty member is the logical choice to have collection development responsibility.

For many years, this rationale was unchallenged or at least unexamined. In time, however, librarians and other academics began to express dissatisfaction with collections built exclusively by faculty. By today's standards the earliest observations of this nature were based on rather primitive evaluations, but they were sufficiently accurate to initiate and sustain a serious questioning of prevailing practice. Though the principle of giving collection development responsibility to subject specialists on the faculty seemed sound, there was a persistent sense that in many instances it did not work. It was difficult for librarians to be critical of the system and for administrators to respond to that criticism because it challenged faculty authority. This also suggested that because library collections were costly, the effectiveness of faculty book selection decisions should be evaluated. Lacking information on the quality of collections, academic administrators generally could not take corrective action even if it was warranted. Faculty were free to choose new books as they saw fit. Many, of course, executed this duty with skill, but some did not.

During the sixties, when academic budgets grew at an unprecedented rate, collection development work became too burdensome to be accomplished exclu- sively through faculty control. Faculty were teaching more students, doing more research, and publishing more. They did not have the time to make the many selection decisions that were required. Increasingly they asked why they should be doing the library's work and, generally, were relieved when librarians assumed more responsibility for selection. The trend of gradually transferring authority for the collection from faculty to librarians has not been entirely completed.

The significance of this shift of responsibility lies in the fact that it is a de facto modification of a basic, well-established tradition. It is important to note that this was done solely as an expedient way of coping with overwhelming workloads. The change in practice may be inconsistent with tradition, but many faculty continue to believe that total control over the selection of library materials is properly their responsibility. They may be surprised or even angered when local practice limits their role in collection development. They may not like to be constrained by collection policy, or by sharing selection responsibility with librarians. Certainly they would resent having their recommendations rejected by the library. In such a situation the conflict between old and new attitudes can make it very difficult to establish good working relations between librarians and faculty.

Large acquisition budget increases are now infrequent. Nevertheless, few institutions have reinstated exclusive faculty control. Not all librarians have been granted greater control over collections, but generally the new arrangement has wide acceptance. And it seems to work. How well it works has not been determined.

Expanding the authority of librarians in collection development logically leads to the question of whether they must now bring new forms of expertise to their role. One approach is to challenge the assumptions underlying the old practice of relying on the faculty. Is it true, for example, that the person who knows a subject best is the best person to have collection development responsibility? Is it true that the person with a Ph.D. has the breadth and cur- 
rency of knowledge about information resources that are required to maintain a viable collection? By definition and by tradition, the faculty are research specialists. Their primary loyalty is often to a profession rather than to the institution. The library, however, must assemble collections that serve narrow subdisciplines as well as the multidisciplinary needs of the community as a whole. Thus, the scope of faculty interests does not necessarily match those of the library. The critical question is, therefore, whether faculty members can change their perspective to address library and campus needs. In many cases, the answer is yes, but the $\mathrm{Ph}$.D. as credential does not logically or necessarily assure that outcome. Specialized knowledge in a discipline may be necessary, but it is not the only form of expertise required for effective collection development. There is another equally important set of skills. Indeed, the most serious deficiency of faculty-dominated book selection was the failure to recognize the need for any other type of expertise.

Describing and defining these skills would improve our understanding of how increasing the librarians' responsibility for collections changes their role in academic life. While that task is not the purpose of this paper, it is important to note that there is one common trait. They all deal with the practical problems concerning the selection of materials: allocating scarce funds on the basis of program needs, evaluating patterns of use, introducing new electronic technologies as an alternative to printed sources, weeding the collection, maintaining productivity, preserving the collection, and so on. In this regard, the term collection management is probably more accurate than collection development, as the former suggests concerns that are more managerial than academic in nature.

In the affluent sixties many libraries were more concerned with the rapid selection and acquisition of materials than with making the most of a limited budget. The need to deal with a limited budget, however, became increasingly urgent in the seventies and eighties. It became vital to entrust collection building to people who could be objective and rigorous about the priorities necessary to maintain viable collections, people whose abilities went beyond subject knowledge to include good' collection management skills. Librarians increasingly were expected to complement faculty subject expertise with these additional skills. Accordingly, their authority was expanded.

\section{"The slow migration of this respon- sibility from faculties to libraries is 'one of the most significant and origi- nal contributions to the growth of professional librarianship in the United States.'"'}

The slow migration of this responsibility from faculties to libraries is "one of the most significant and original contributions to the growth of professional librarianship in the United States. ${ }^{\prime 8}$ Its repercussions have been evident. For example, the shift in responsibility has strengthened the case for faculty status for librarians, since they have assumed what were once predominantly faculty responsibilities. In collection management, too, the expanded role of librarians has been significant as many initiated systematic evaluations of collection quality.

For generations librarians had expressed misgivings about the adequacy of collections built under the facultydominated system. However, it was difficult to confirm or dispel these suspicions due to the prevailing politics of the bimodal academic organizational structure. Librarians, typically nonfaculty, were not expected to criticize faculty. Library collections, however, because of their high cost, had attracted the concern of many academic administrators, especially those who believed that more control over the academic sector was needed to operate effectively within reduced budgets. They wanted to know if less money could be spent on library books without harming the teaching and research programs. Therefore, at some institutions, librarians 
discovered that they not only had the freedom to conduct collection assessments, but they also had unprecedented support from the central administration for such reviews.

Before 1950 most studies of library collections took the form of descriptive surveys that drew heavily on information provided by faculty. The 1933 review at the University of Chicago stands as an early exception, but very few were analytical or systematic in their approach to correlating strengths and weaknesses in the collection with program needs.

In the years since the Chicago study, libraries have conducted many critical collection evaluations, and a sizable literature on methodology has come into existence. ${ }^{9}$ In 1979 the University of Pittsburgh published the alarming results of a major analysis of how its library was being used. ${ }^{10}$ This study attempted to prove that too many books were unused. Its conclusion that nearly 40 percent of all books had not circulated during the first six years after being accessioned seemed to substantiate that claim. The wastefulness and misjudgment implied by the Pittsburgh study moved many academics, including librarians, to launch a vigorous attack on the study's methods and, thus, on the validity of the results.

\section{"The wastefulness and misjudgment implied by the Pittsburgh study moved many academics, including li- brarians, to launch a vigorous attack on the study's methods and, thus, on the validity of the results."}

The intensity of the controversy provoked by the Pittsburgh study is indicative of conflicts inherent in the academic tradition. In one sense, the study appears to be an indictment of faculty because it demonstrates that there has been substantial waste of financial resources in an area where faculty traditionally have had primary responsibility. However, many have seen the study as an indictment of the quest for cost-efficient management in the academic environment. As one critic states, the study "does not demonstrate a comprehension of the purpose of an academic research or university library."

From the first perspective of seeking to prevent wastefulness in the library, it seems obvious that avoidance of such misspending would improve the effectiveness of current programs. This is generally the point of view of administrators. The opposing perspective, usually that of the faculty, is that library collections should reflect current publishing in the disciplines regardless of current or prospective use of the material. These conflicting points of view are rooted in a larger issue, the tension between the needs of the institution and the needs of the academic professions. Institutions, especially in periods of fiscal constraint, are primarily concerned with acquiring only the resources their programs need. They are at the mercy of their local fiscal problems. Academic professions, however, are concerned with advancing knowledge in the disciplines on a world scale, and the support of academic institutions is essential to their success. Therefore, it seems almost inevitable that by granting collection development authority to faculty, a group whose first loyalty is to their profession, without stating guidelines for their accountability, library collections will tend to reflect the interests of the professions rather than the needs of the institution.

Many academics believe that a symbiotic relationship exists between universities and the professions. Nurturing this relationship is essential to the health of both organizations and to the advancement of knowledge itself. In their pursuit of greater cost-effectiveness at the local level, however, institutions may jeopardize this relationship. This threat may be apparent in areas such as collection development where the reduction of faculty authority and the increase of administrative control may lead to the imposition of economic controls based only on a narrow interpretation of campus needs. From this perspective the main failure of the Pittsburgh study was that it did not acknowl- 
edge the "library problem" as a symptom of a much larger problem. When, in the final report, the issue of unused books is addressed, it is stated that the answers "are likely to influence librarianship and libraries in dramatic ways." It did not say that the answers were also likely to influence teaching and research in dramatic ways.

At the time of the Pittsburgh study a sense emerged that dysfunctions such as the "library problem" could be better understood by examining the total system of scholarly communication. Indeed, other groups were also experiencing difficulties. In the mid-seventies, the American Council of Learned Societies (ACLS) responded to concerns throughout the academic community by conducting a nationwide enquiry into the state of scholarly communications. ${ }^{12}$

The ACLS survey, commonly known as the "National Enquiry," took a broad perspective and, unlike the Pittsburgh study, it did not present preconceived conclusions. A respect for the cooperative nature of scholarly communications is reflected throughout the enquiry's final report and recommendations. Emphasized is the need to foster voluntary consultation among the members of the system by building a better understanding of how the whole system works. To this end, the Office of Scholarly Communication was founded in 1984. It supported a continuing critical monitoring of all aspects of the network. More recently, the Association of Research Libraries turned its attention to the influence of the broader environment on libraries by establishing its own Task Force on Scholarly Communications. $^{13}$

Though different in their methods, both the National Enquiry and the Pittsburgh Study focus on the common issue of costeffectiveness in scholarly communication. This is fundamentally a question of reconciling ends and means. Can scholarly. activity use financial resources more efficiently without impeding the advancement of learning and creativity? Or, stated from another perspective, can the growth of knowledge be accelerated by eliminating waste and improving efficiency within the scholarly communication system?

Phrasing the question the first way implies that the levels of efficiency or conversely, wastefulness, proper to scholarship are not yet known, and that the search for improvement must address the needs of the total system. John William Ward, president of ACLS, takes this position:

Without the participation of scholars, the system will evolve according to administrative, financial, and technical imperatives. The great danger is that we will end up with a system of scholarly communication which will be economically and technically viable, but not intellectually desirable. ${ }^{14}$

The implications of the second formulation of the question, however, are more serious. As stated, it assumes that the existing system is wasteful, and that scholarship will be served best by eliminating waste as quickly as possible. Despite these differences in perspective both studies seem to agree on one major point: more money is not the answer. ${ }^{15}$

In 1985 the ACLS conducted a second survey. ${ }^{16}$ In that study, 45 percent of the respondents viewed book holdings in their campus libraries as only "fair" or "poor" in meeting their research needs. Thirty-five percent said the same about journal holdings. This suggests that there are many scholars who find collections to be inadequate. The contradiction between this conclusion and the claim of the Pittsburgh study that collections are significantly underused remains to be explained. Are collections too large or not large enough? Is the selection of materials effectively coordinated with campus programs? Or is research too capricious and wide-ranging to permit the development of strong collection support? Questions like these can only be answered after establishing wider agreement on what constitutes adequacy.

Cost-effectiveness should be a basic objective in managing library collections. It is difficult, however, to plan and develop collections economically when fundamental issues about authority, expertise, and purpose remain open. As these problems are rooted in traditions that shape faculty 
behavior, local administrations are not always willing or able to establish policies that provide clear guidelines for the managers of information resources, especially if doing so means encountering faculty resistance. The daily work of managing academic library collections, therefore, is typ- ically done despite fundamental ambiguities that have yet to be resolved. Though faculty and librarians working in a cooperative spirit may make the best decisions they can on a daily basis, the challenge of economically yet systematically building more effective collections persists.

\section{REFERENCES}

1. Robert H. Roy, The Cultures of Management (Baltimore: Johns Hopkins Univ. Pr., 1977), p.88.

2. Karl E. Weick, "Educational Organizations as Loosely Coupled Systems," Administrative Science Quarterly 21:1-19 (Mar. 1976).

3. Peter F. Drucker, Managing in Turbulent Times (New York: Harper, 1980), p.130.

4. John W. Meyer and Brian Rowan, "The Structure of Educational Organizations," in Organizational Environments: Ritual and Rationality, ed. John W. Meyer and W. Richard Scott (Beverly Hills, Calif.: Sage, 1983), p.71-97.

5. Sanford M. Dornbusch and W. Richard Scott, Evaluation and the Exercise of Authority (San Francisco: Josey-Bass, 1977), p.233.

6. Norman H. Dudley, "Organization Models for Collection Development," in Collection Development in Libraries: A Treatise, ed. Robert D. Stueart and George B. Miller, Jr. (Greenwich, Conn.: JAI Pr., 1980), p.20-27.

7. David O. Lane, "The Selection of Academic Library Materials, a Literature Survey," College and Research Libraries 29:364-72 (Sept. 1968).

8. Paul H. Mosher, "Collection Evaluation in Research Libraries: The Search for Quality, Consistency, and System in Collection Development," Library Resources \& Technical Services 23:20-32 (Winter 1979).

9. Paul H. Mosher, "Quality and Library Collections: New Directions in Research and Practice in Collection Evaluation," Advances in Librarianship 13:211-38 (1984).

10. Alan Kent and others, Use of Library Materials: The University of Pittsburgh Study (New York: Dekker, 1979).

11. Jasper G. Schad and others, "Pittsburgh University Studies of Collection Usage: A Symposium," Journal of Academic Librarianship 5:60-70 (May 1979).

12. National Enquiry into Scholarly Communication, Scholarly Communication: The Report of the National Enquiry, (Baltimore: Johns Hopkins Univ. Pr., 1979).

13. ARL Task Force on Scholarly Communication, The Changing System of Scholarly Communication (Washington, D.C.: Assn. of Research Libraries,1986).

14. Scholarly Communication 1:1 (June 1985).

15. H. William Axford, "Academic Library Management Studies: From Games to Leadership," Advances in Librarianship 10:53-61 (1980).

16. Herbert C. Morton and Anne Jamieson Price, "The ACLS Survey of Scholars: Views on Publications, Computers, Libraries," Scholarly Communication 5:11-14 (Summer 1986). 